\title{
Patients in Northwestern Turkey Prefer Herbs as Complementary Medicine after Breast Cancer Diagnosis
}

\author{
Bahadir M. Gulluoglu Asim Cingi $^{\mathrm{b}}$ Tebessum Cakir ${ }^{\mathrm{b}}$ Afsar Barlas ${ }^{\mathrm{b}}$ \\ a Department of General Surgery, Breast and Endocrine Surgery Unit, \\ ${ }^{b}$ Department of General Surgery, Marmara University School of Medicine, Istanbul, Turkey
}

\section{Key Words}

Breast cancer · Complementary medicine .

Supportive care - Therapy

\section{Summary}

Background: A cross-sectional survey was conducted in order to define the prevalence, pattern, and predictors of complementary and alternative medicine (CAM) use in breast cancer patients in northwestern Turkey. Patients and Methods: All patients admitted to the breast center between January 2005 and January 2006 were consecutively included in the study. Demographics and clinical data of study patients were noted. A 15-item questionnaire was used to document the attitude of breast cancer patients towards CAM modalities. Primary outcomes were prevalence, pattern, and predictors of CAM. Secondary outcomes were the reasons for CAM use, the number and type of adverse events related to CAM use, and the satisfaction level of CAM users. Results: Nearly one third of breast cancer patients use at least one type of CAM in addition to conventional therapy. Most chose herbal medicines which they think support their general health status. Nettle (Urtica diocia/U. urens) was the most common herbal medicine that patients consume. Previous experience with CAM was the most significant factor for CAM use after breast cancer diagnosis. Being young and married as well as receiving radiotherapy were among other independent factors for using any CAM modality.
Zusammenfassung

Brustkrebs · Komplementärmedizin .

Unterstützende Pflege · Therapie

\section{Schlüsselwörter}

Hintergrund: In einer Querschnittsstudie sollten Prävalenz, Muster und Prädiktoren der Nutzung von Komplementär- und Alternativmedizin (CAM) bei Brustkrebspatientinnen im Nordwesten der Türkei bestimmt werden. Patientinnen und Methoden: Alle zwischen Januar 2005 und Januar 2006 an das Brustzentrum überwiesenen Patientinnen wurden in die Studie aufgenommen. Die demographischen und klinischen Daten der Studienpatientinnen wurden erfasst. Mit einem aus 15 Items bestehenden Fragebogen wurde die Einstellung der Brustkrebspatientinnen zu verschiedenen CAM-Modalitäten dokumentiert. Primäre Endpunkte wa-ren Prävalenz, Muster und Prädiktoren der CAM-Nutzung. Sekundäre Endpunkte waren die Gründe für die Anwendung von CAM, Anzahl und Art damit verbundener Nebenwirkungen sowie die Zufriedenheit der CAM-Nutzer. Ergebnisse: Fast ein Drittel der Brustkrebspatientinnen wendet mindestens eine Art von CAM zusätzlich zur konventionellen Therapie an. Die meisten Patientinnen nutzen Heilkräuter, von denen sie glauben, dass sie die allgemeine Gesundheit fördern. Nesseln (Urtica diocia/U. urens) werden am häufigsten angewandt. Bereits bestehende Erfahrung mit CAM war der maßgeblichste Faktor für die Anwendung von CAM nach einer Brustkrebsdiagnose. Junges Alter, Familienstand verheiratet sowie die Behandlung mit Radiotherapie gehörten unter anderem zu den unabhängigen Faktoren für die Nutzung einer CAMModalität.

\section{KARGER}

Fax +497614520714

Information@Karger.de

www.karger.com
(C) 2008 S. Karger GmbH, Freiburg

www.karger.com/brc 


\section{Introduction}

The average prevalence of complementary and alternative medicine (CAM) use has been reported to be around $30 \%$ in different studies [1]. These studies documented that $15-83 \%$ of breast cancer patients use CAM [2-8]. The prevalence and characteristics of CAM use varied from nation to nation [8]. By definition, complementary treatment is the type of therapy which is administered along with the conventional methods in order to treat an illness [9]. In contrast to this, alternative treatment is the type of therapy which is administered as a replacement for conventional methods [9]. CAM includes a variety of behavioral techniques (mind therapies) and clinical approaches (body therapies). Behavioral techniques involve spiritual techniques and relaxation methods, whereas clinical approaches involve therapies such as massage, herbal medicine use, and chiropractic applications [5]. The objectives of CAM use are manifold including reducing toxicities related to therapy, improving cancer-related symptoms, enhancing the immune system, and obtaining anticancer effects $[10,11]$. Gender, age, educational status, income of patients, as well as disease stage are found to be related to the frequency of CAM usage [6]. CAM use was also found to be related to the level of increased anxiety due to anticipation of breast cancer-related recurrences or death [3]. Previous studies from Turkey, which reported characteristics of CAM use, provided general data retrieved from all types of cancer cases. There has been no single study reporting breast cancer-specific findings regarding CAM. Overall, the prevalence of CAM use was found to be $36-52 \%$ in Turkish patients [12-15]. We conducted a cross-sectional survey in order to define the prevalence, patterns, and predictors of CAM use in patients with breast cancer at northwestern Turkey.

\section{Patients and Methods}

\section{Patients}

All patients who had been admitted consecutively to the follow-up clinics at the Breast Center of the Marmara University Hospital between January 2005 and January 2006 were within the scope of the study. The Marmara University School of Medicine Research Ethics Committee approved the study protocol. Only patients who had given oral and written consent were asked to complete the survey. Inclusion criteria were having undergone surgery for breast cancer at least 12 months ago, and having given consent. Exclusion criteria included having received surgical treatment for breast cancer more than 5 years ago, having developed locoregional and/or distant recurrence within the previous 12 months, and having declined to give consent.

\section{Collection of Data}

Demographic data of patients including their age, marital status, and educational level were recorded on a standard chart. Patients' pathological stage of the disease as well as treatment details including surgery, chemotherapy (CT), radiotherapy (RT), and hormonal therapy (HT) were retrieved from their hospital files.
Survey Instrument (Questionnaire)

The survey used a self-administered questionnaire. All patients completed the questionnaire under the supervision of one of the study authors (T.C.). The questionnaire included 15 questions. It was designed to obtain data regarding: a) adverse events during or after the conventional cancer treatment; b) frequency of anxiety due to breast cancer; c) adverse events related to the conventional treatment; d) CAM use before breast cancer diagnosis; e) CAM use after breast cancer diagnosis; f) timing of CAM use relative to conventional treatment (before, during, or after); g) duration of CAM use (for patients who used CAM after the breast cancer diagnosis); h) type(s)/name(s) of CAM modalities which the patient used; i) purpose of CAM use; j) awareness of primary physicians of their patient's preference for CAM use; k) attitude of primary physician(s) towards the patient's choice (provided they had been properly informed); 1) the patient's source of information on CAM; m) level of well-being during or after receiving CAM; $n$ ) presence of any adverse events attributable to CAM; and o) likelihood of patient recommending CAM to others.

Patients were asked to answer 10 questions (items a, c, d, e, f, i, j, k, l, o) by choosing among a list of choices, 2 questions (items b, m) on a 10-cm long visual analog scale, and 2 questions (items $g, n$ ) by filling the blank (openended question). At item h, 12 CAM modality choices were given, and the patients were asked to indicate how frequently they used each one of them. Findings regarding 'purpose of CAM use', 'patient's information source about CAM and its modalities', 'physicians' awareness about their patient's CAM use', and 'physicians' attitude towards their patient's CAM use' were assessed as 'motives' for CAM use.

\section{Outcomes}

Primary outcomes were prevalence of CAM use in Turkish breast cancer patients, patterns of CAM use, and predictors of CAM use. Secondary outcomes were reasons for CAM use, number and type of adverse events related to CAM use, and satisfaction level of CAM users.

\section{Statistics}

All comparisons were made between CAM users and non-users. An independent samples t-test was done for continuous random variables. Continuous data were summarized as mean \pm standard deviation (SD). A chisquare test $\left(\xi^{2}\right)$ was done for discrete random variables. A p value $<0.05$ was considered significant. Significant factors retrieved from univariate analysis were further tested by multivariate analysis by binomial logistic regression in order to determine independent factors for CAM use. A computer-based program (v 11.5; SPSS, Chicago, IL, USA) was used for all statistical analysis.

\section{Results}

\section{Patient Demographics and Clinical Features}

A total of 129 patients who had been admitted to the followup clinics at the Breast Center of the Marmara University Hospital and met the inclusion criteria were included in the study. All patients were residing in the Marmara region which geographically constitutes the complete north-west of Turkey including the Istanbul province. The mean duration between surgical treatment and survey interview was 39.8 (17-60) months. All patients were women. The mean age of the patients was 57.4 (28-86) years. The majority of patients $(\mathrm{n}=86$; $67 \%$ ) were married. Graduates of primary school $(n=53$; $41 \%$ ) constituted the largest group. Most patients ( $n=61$; $47 \%$ ) had stage II cancer. The majority of patients ( $n=76$; $59 \%$ ) underwent modified radical mastectomy including level 
Table 1. Prevalence and patterns of complementary and alternative medicine (CAM) use in study patients

\begin{tabular}{|c|c|c|c|c|c|c|}
\hline \multirow[t]{2}{*}{ Modality } & \multicolumn{6}{|c|}{ Patients using CAM, n $\left(\%^{a}\right)$} \\
\hline & Never & Rarely & $\begin{array}{l}\text { Occasio- } \\
\text { nally }\end{array}$ & Often & $\begin{array}{l}\text { Regu- } \\
\text { larly }\end{array}$ & Total use \\
\hline Herbal medicine & 98 & 9 & 12 & 2 & 8 & $31(67)$ \\
\hline Spiritual $^{\mathrm{b}}$ & 118 & 1 & 1 & 3 & 6 & $11(24)$ \\
\hline Nutritional support ${ }^{\mathrm{c}}$ & 119 & 2 & 4 & 1 & 3 & $10(22)$ \\
\hline Dietary regulation & 124 & 1 & 1 & 0 & 3 & $5(11)$ \\
\hline Physical exercise $^{\mathrm{d}}$ & 124 & 1 & 0 & 0 & 4 & $5(11)$ \\
\hline Musical therapy & 127 & 1 & 0 & 0 & 1 & $2(4)$ \\
\hline Massage & 128 & 1 & 0 & 0 & 0 & $1(2)$ \\
\hline Acupuncture & 128 & 0 & 0 & 1 & 0 & $1(2)$ \\
\hline Meditation & 128 & 0 & 0 & 0 & 1 & $1(2)$ \\
\hline Aromatherapy & 129 & 0 & 0 & 0 & 0 & $0(0)$ \\
\hline Support group & 129 & 0 & 0 & 0 & 0 & $0(0)$ \\
\hline Other & 128 & 0 & 1 & 0 & 0 & $1(2)$ \\
\hline
\end{tabular}

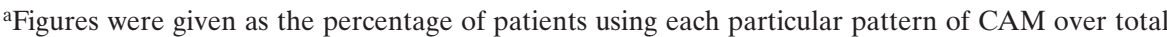
number of patients who used any type of CAM $(n=46)$. Due to some patients' preference for using more than 1 pattern of CAM, the sum of percentages exceeds 100 on the table.

bIncluding patterns such as to worship, or consultation with a religious man.

'Including vitamins, mineral supplements, and over-the-counter immunosupportive drugs.

dincluding yoga.

eThermotherapy at hot springs.
I-II axillary dissection. 81 (63\%) patients received CT, and 66 $(51 \%)$ patients received RT after surgery. $100(78 \%)$ patients received or are currently receiving HT.

\section{Prevalence}

$46(36 \%)$ patients declared that they used at least 1 form of CAM after breast cancer surgery. All patients used CAM as a complementary treatment. Only $13(10 \%)$ patients reported that they had experience with CAM use before the cancer diagnosis.

\section{Patterns}

The median duration of CAM use was 6 (1-50) months. 13 ( $28 \%$ ) of the 46 patients using CAM stated that they used more than 1 form. 31 patients (67\%) consumed some form of herbal medicine. Other common CAM modalities were spiritual and nutritional support (24 and 22\%, respectively; table 1). Among the herbal medicines, nettle (Urticae diocia/U. urens) was overwhelmingly the most commonly used type (77\%). Other herbal medicines which patients reported that they had consumed were green tea (Camellia sinensis; 16\%), black cumin (Nigella sativa; 10\%), flax seed oil (Linum usitatissimum; 10\%), honey (Mielbol; 10\%), bee pollen, powder (6\%), aloe vera (Aloexylon agallocum; 6\%), broccoli (Brassica oleracea; 6\%), Chinese tea (Camellia sinesis; 3\%), camomile (Matricaria chamomilla; 3\%), carrot juice (Daucus carota; 3\%), hibiscus (Hibiscus rosa-sinensis; 3\%), lathyrus (Semen lathyri; 3\%), orange blossom (Cytrus aurantium; 3\%), ginseng (Panax ginseng; 3\%), grape seed (Vitis vinifera; 3\%), mallow (Malva sylvestris; 3\%), yarrow (Achillea millefolium;3\%), and camphor (Cinnamomum camphorea; $3 \%$ ).

\section{Predictors}

Univariate analysis revealed that a younger patient age, being married, receiving either CT or RT, frequent anxiety episodes, and a previous history of CAM use were significant factors for CAM use preference after breast cancer diagnosis. The mean age of patients using CAM therapy (52 \pm 11 years) was significantly less than the age of non-users $(60.3 \pm 14 ; \mathrm{p}=0.001)$. Married women constituted a significantly larger group of CAM users than non-users ( 83 vs. $58 \% ; \mathrm{p}=0.015$ ). Significantly more patients (76\%) among CAM users had a history of receiving CT when compared to non-users $(55 \%$; $\mathrm{p}=0.023)$. Similarly, receiving postoperative RT was also found to be a significant factor for CAM use ( $65 \%$ of CAM users vs. $43 \%$ of non-users; $p=0.027)$. The frequency of anxiety was more intense in CAM users when compared to non-users $(4.57 \pm 3.3$ $\mathrm{cm}$ vs. $3.12 \pm 3.1 \mathrm{~cm}$, respectively; $\mathrm{p}=0.015)$. Also, significantly more patients among CAM users $(22 \%)$ had a history of previous CAM use than among non-users $(4 \% ; p=0.002)$. The patients' education level, type of surgery, receiving HT, tumor stage, presence, and number of adverse events due to conventional treatment modalities did not show any difference between CAM users and non-users (table 2). Logistic regression analysis showed that using CAM prior to cancer diagnosis ( $\mathrm{p}=$ $0.001)$, being married $(p=0.015)$, being younger $(p=0.029)$, and receiving RT $(\mathrm{p}=0.047)$ independently predicted CAM use.

\section{Motives, Adverse Events, and Satisfaction}

The most common reason for CAM use among patients was 'to improve general health status $(\mathrm{n}=21 ; 46 \%)$ '. Information about CAM was most commonly obtained through 'personal 
communication with relatives or friends (word of mouth; $\mathrm{n}=$ $28 ; 61 \%)$ '. 28 (61\%) patients who used CAM informed their primary physicians about their CAM use. The physicians of 13 (46\%) patients supported CAM use. Only 1 case of a contact sore due to CAM use was reported as an adverse event. In patients using CAM modalities, the median satisfaction level was $5(0-10) \mathrm{cm}$. The satisfaction level of $20(43 \%)$ patients was high; of those, 10 (22\%) were completely satisfied.

\section{Discussion}

In this cross-sectional survey, it was found that nearly one third of breast cancer patients residing in northwestern Turkey used CAM after they received their diagnosis. All patients indicated that they used CAM as complementary to the recommended conventional treatment modalities. Improving general health status was the main reason for using different types of CAM modalities in nearly half of the patients. The majority of the patients preferred to use herbal medicines among different modalities. It was found that previous experience of any of the CAM modalities, being married, being relatively young, and receiving radiotherapy were independent predictors for CAM use.

There are previous studies from Turkey describing the patterns of CAM use among both adult and pediatric oncology patients [12-15]. However, those studies used samples that were different to ours. They reported results of CAM use in patients with various cancer types. Our study exclusively assessed breast cancer cases in a geographically defined Turkish population, and gave the prevalence and patterns of their CAM use. Therefore, the findings of the present study partially reflect the characteristics of CAM use among Turkish breast cancer patients and the interference of this use with conventional treatment modalities. However, there are considerable drawbacks to our study. The sample size of the study was small. Also, the survey had certain limitations: First, there was no prior study which tested its validation. The survey included questions of various types which may have confused the patients. We tried to optimize the comprehension of the questions by escorting all patients during the survey. The number of choices for certain questions were limited, which might have prevented patients from giving different answers beyond the available choices. Also, the presence of an interviewer may have influenced the results due to the patients' reluctance to give the most appropriate answers in that setting. Since the present study assessed the characteristics of CAM use, we did not provide any prognostic parameter related to its use.

A considerable percentage $(36 \%)$ of our patients indicated that they used CAM. Although this figure is in accordance with previous studies $[3,5,8,12-16]$, it is considerably lower than some large series from the UK and the US $[4,6,7,17]$. Cultural background and traditional differences may explain this relatively less prevalent use of CAM in northwestern
Table 2. Comparison of study groups regarding patients' features

\begin{tabular}{|c|c|c|c|}
\hline Features & $\begin{array}{l}\text { CAM } \\
\text { users } \\
(n=46)\end{array}$ & $\begin{array}{l}\text { CAM } \\
\text { non-users } \\
(\mathrm{n}=83)\end{array}$ & $\mathrm{p}$ \\
\hline Age, mean, years (SD) & $52(11)$ & $60.3(14)$ & 0.001 \\
\hline Marital status, n (\%) & & & 0.015 \\
\hline Single & $2(4)$ & $11(13)$ & \\
\hline Married & $38(83)$ & $48(58)$ & \\
\hline Divorced/widowed & $6(13)$ & $24(29)$ & \\
\hline Education level, n (\%) & & & 0.77 \\
\hline Illiterate & $2(4)$ & $4(5)$ & \\
\hline Literate without school & $3(6)$ & $4(5)$ & \\
\hline Primary school & $15(32)$ & $38(45)$ & \\
\hline High school & $12(26)$ & $20(24)$ & \\
\hline University & $6(13)$ & $8(10)$ & \\
\hline Doctorate & $8(19)$ & $9(11)$ & \\
\hline Type of surgery, n (\%) & & & 0.32 \\
\hline Lumpectomy only & $1(2)$ & $9(11)$ & \\
\hline Simple mastectomy & $2(4)$ & $7(8)$ & \\
\hline $\mathrm{BCS}$ & $14(31)$ & $18(22)$ & \\
\hline MRM & $28(61)$ & $48(58)$ & \\
\hline $\mathrm{MRM}+$ reconstruction & $1(2)$ & $1(1)$ & \\
\hline Receiving chemotherapy, n (\%) & & & 0.023 \\
\hline Yes & $35(76)$ & $46(55)$ & \\
\hline No & $11(24)$ & $37(45)$ & \\
\hline Receiving radiotherapy, $\mathrm{n}(\%)$ & & & 0.027 \\
\hline Yes & $30(65)$ & $36(43)$ & \\
\hline No & $16(35)$ & $47(57)$ & \\
\hline Receiving hormone therapy, n (\%) & & & 0.19 \\
\hline Yes & $39(85)$ & $61(73)$ & \\
\hline No & $7(15)$ & $22(27)$ & \\
\hline Tumor stage, n (\%) & & & 0.48 \\
\hline 0 & $0(0)$ & $2(2)$ & \\
\hline I & $16(35)$ & $25(30)$ & \\
\hline II & $19(41)$ & $42(51)$ & \\
\hline III & $6(13)$ & $8(10)$ & \\
\hline IV & $5(11)$ & $6(7)$ & \\
\hline Frequency of anxiety, mean, cm (SD) & $4.57(3.3)$ & $3.12(3.1)$ & 0.015 \\
\hline Presence of any adverse event ${ }^{\mathrm{a}}, \mathrm{n}(\%)$ & & & 0.11 \\
\hline Yes & $43(93)$ & $68(82)$ & \\
\hline No & $3(7)$ & $15(18)$ & \\
\hline Number of adverse events ${ }^{\mathrm{a}}, \mathrm{n}(\%)$ & & & 0.07 \\
\hline 0 & $3(7)$ & $15(18)$ & \\
\hline $1-4$ & $28(60)$ & $50(60)$ & \\
\hline $5-8$ & $15(33)$ & $15(18)$ & \\
\hline 9 and more & $0(0)$ & $3(4)$ & \\
\hline Previous history of CAM use, n (\%) & & & 0.002 \\
\hline Yes & $10(22)$ & $3(4)$ & \\
\hline No & $36(78)$ & $80(96)$ & \\
\hline
\end{tabular}

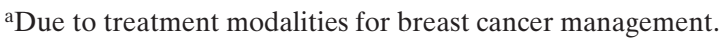

$\mathrm{CAM}=$ Complementary and alternative medicine; $\mathrm{SD}=$ standard deviation; BCS = breast conserving surgery (including level I-II axillary dissection); $\mathrm{MRM}=$ modified radical mastectomy (including level I-II axillary dissection).

Turkey. The finding which must be underlined is that all study patients regarded CAM as complementary. No single patient used it as an alternative for the recommended conventional treatment modalities. The main reason for CAM use was to improve the general health status in our study population, and this was no different from other studies in which the motives 
of CAM use were therapeutic and psychological [17], i.e. to relieve symptoms $[4,7,17]$ or to gain a sense of control over life and to improve quality of life [4].

More than half of the CAM users consumed herbal medicines. Among the herbs, patients reported that they consumed nettle most commonly. Although previous human studies reported that nettle caused various adverse effects such as decreasing blood glucose level, having abortive and uterine stimulant effects, and causing diarrhea and allergic skin reactions [18], only 1 significant side effect was identified during the survey. Other CAM modalities which patients preferred to use were nutritional and religious support. In similar studies from other geographic areas, vitamins, herbal medicines, and spiritual practices were found to be the most common modalities $[4,6$, $7,17]$. Less than one third of the patients in this study preferred to use more than 1 CAM modality, which is a different patient attitude from other populations. Patients from Western countries frequently choose to use more than 1 modality [19]. In this study, it was shown that the majority of the patients let their primary physician know about their CAM preferences. Interestingly, nearly half of the physicians who knew about their patient's CAM use supported their patients in their choice. This finding is in sharp contrast to the attitudes of physicians from Western countries. A study from Norway showed that only $4 \%$ of physicians backed their patients' choice for using a CAM modality [20]. However, the Norwegian study was multi-institutional whereas ours is a single center study. Therefore, our study would not appropriately represent nationwide characteristics of physician attitude patterns towards CAM.
Nearly half of the patients regarded their satisfaction level with the CAM experience as above average and reported that they would recommend the modality to others. In the present study, previous experience of CAM use, younger age, being married, and receiving RT independently predicted CAM use. In similar studies, CAM users were also more likely to be younger [3, 19], married [19], more educated [2, 3, 6], and wealthier $[2,3,19]$. Interestingly, in our patients receiving CT, CAM use did not reach statistical significance after a multivariate analysis. However, RT was found to be a significant factor. Similar studies showed that both CT and RT were strong predictors for CAM use [21].

As a conclusion, nearly one third of breast cancer patients at northwestern Turkey prefer to use at least 1 type of CAM as complementary therapy. Most choose herbal medicines which they think support their general health status. Patients choose herbal medicines more frequently and do not use other modalities as frequently as they are used in Western countries. Nettle is by far the most common herbal medicine that patients consume. Although a few people experience CAM before cancer diagnosis, this prior experience of CAM use is the most significant factor for its use after diagnosis. Being young and married as well as receiving RT are among other independent factors for using any CAM modality in breast cancer patients in northwestern Turkey.

\section{Acknowledgement}

The authors appreciate Prof. Ray Guillary's help in revising the manuscript.

\section{References}

1 Ernst E, Cassileth BR: The prevalence of complementary/alternative medicine in cancer: a systematic review. Cancer 1998;83:777-82.

$\checkmark 2$ Catt S, Fallowfield L, Langridge C: What non-prescription treatments do UK women with breast cancer use? Eur J Cancer Care 2006;15:279-85.

$\checkmark 3$ Rakovitch E, Pignol JP, Chartier C, Ezer M, Verma $\mathrm{S}$, Dranitsaris G, Clemons M: Complementary and alternative medicine use is associated with an increased perception of breast cancer risk and death. Breast Cancer Res Treat 2005;90:139-48.

4 Boon H, Stewart M, Kennard MA, Gray R, Sawka C, Brown JB, McWilliam C, Gavin A, Baron RA, Aaron D, Haines-Kamka T: The use of complementary/alternative medicine by breast cancer survivors in Ontario: Prevalence and perceptions. J Clin Oncol 2000;18:2515-21.

5 Burstein HJ, Gelber S, Guadagnoli E, Weeks J: Use of alternative medicine by women with early-stage breast cancer. N Engl J Med 1999;340:1733-9.

6 Ashikaga T, Bosompra K, O'Brien P, Nelson L: Use of complementary and alternative medicine by breast cancer patients: prevalence, patterns and communication with physicians. Support Care Cancer 2002;10:542-8.

7 Richardson MA, Sanders T, Palmer JL, Greisinger A, Singletary SE: Complementary/alternative medicine use in a comprehensive cancer centre and the implications of oncology. J Clin Oncol 2000;18: 2505-14.
8 Molassiotis A, Margulies A, Fernandez-Ortega P, Pud D, Ozden G, Scott JA, Panteli V, Margulies A, Browall M, Magri M, Selvekerova S, Madsen E, Milovics L, Bruyns I, Gudmundsdottir G, Hummerston S, Ahmad AM, Platin N, Kearney N, Patiraki E: Use of complementary and alternative medicine in cancer patients: a European survey. Ann Oncol 2005;16:655-63.

9 Hawks JH, Moyad MA: CAM: Definition and classification overview. Urol Nurs 2003;23:221-3.

10 Tagliaferri M, Cohen I, Tripathy D: Complementary and alternative medicine in early-stage breast cancer. Semin Oncol 2001;28:121-34.

11 Rees RW, Feigel I, Vickers A, Zollman C, McGurk $\mathrm{R}$, Smith C: Prevalence of complementary therapy use by women with breast cancer: a populationbased study. Eur J Cancer 2000;36:1359-64.

12 Tas F, Ustuner Z, Can G, Eralp Y, Camlica H, Basaran M, Karagol H, Sakar B, Disci R, Topuz E: The prevalence and determinants of the use of complementary and alternative medicine in adult Turkish cancer patients. Acta Oncol 2005;44:161-7.

13 Isikhan V, Komurcu S, Ozet A, Arpaci F, Ozturk B, Balbay O, Guner P: The status of alternative treatment in cancer patients in Turkey. Cancer Nurs 2005;28:355-62.

14 Algier LA, Hanoglu Z, Ozden G, Kara F: The use of complementary and alternative (non-conventional) medicine in cancer patients in Turkey. Eur J Oncol Nurs 2005;9:138-46.
5 Karadeniz C, Pinarli FG, Oguz A, Gursel T, Canter $\mathrm{B}$ : Complementary / alternative medicine use in a pediatric oncology unit in Turkey. Pediatr Blood Cancer 2007;48:540-3.

16 Eustachi E: Complementary therapies in breast cancer patients. Breast Care 2007;2:209-16.

17 Shen J, Andersen R, Albert PS, Wenger N, Glaspy J, Cole M, Shekelle P: Use of complementary / alternative therapies by women with advanced stage breast cancer. BMC Complement Altern Med 2002; $2: 8$.

18 Rodriguez-Fragoso L, Reyes-Esparaza J, Burchiel SW, Herrera-Ruiz D, Torres E: Risks and benefits of commonly used herbal medicines in Mexico. Toxicol Appl Pharmacol 2008;227:125-35.

19 Helyer LK, Chin S, Chui BK, Fitzgerald B, Verma S, Rakovitch E, Dranitsaris G, Clemons M: The use of complementary and alternative medicines among patients with locally advanced breast cancer - a descriptive study. BMC Cancer 2006;6:39.

20 Risberg T, Kolstad A, Bremmes Y, Holte H, Wist EA, Mella O, Klepp O, Wilsgaard T, Cassileth BR: Knowledge of and attitudes toward complementary and alternative therapies: a national multicentre study of oncology professionals in Norway. Eur J Cancer 2004;40:529-35.

21 Cui Y, Shu XO, Gao Y, Wen W, Ruan ZX, Jin F, Zheng W: Use of complementary and alternative medicine by chinese women with breast cancer. Breast Cancer Res Treat 2004;85:263-70. 